The University of San Francisco

USF Scholarship: a digital repository @ Gleeson Library |

Geschke Center

Environmental Science

College of Arts and Sciences

2011

\title{
Diversity-Function Relationships Changed in a Long-Term Restoration Experiment
}

James M. Doherty

John Callaway

University of San Francisco, callaway@usfca.edu

Joy B. Zedler

Follow this and additional works at: http://repository.usfca.edu/envs

Part of the Environmental Sciences Commons

\section{Recommended Citation}

James M. Doherty, John Callaway and Joy B. Zedler. Diversity-function relationships changed in a long-term restoration experiment. Ecological Applications. Vol. 21, No. 6 (September 2011), pp. 2143-2155.

This Article is brought to you for free and open access by the College of Arts and Sciences at USF Scholarship: a digital repository @ Gleeson Library | Geschke Center. It has been accepted for inclusion in Environmental Science by an authorized administrator of USF Scholarship: a digital repository @ Gleeson Library | Geschke Center. For more information, please contact repository@usfca.edu. 


\title{
Diversity-function relationships changed in a long-term restoration experiment
}

\author{
James M. Doherty, ${ }^{1,3}$ John C. Callaway, ${ }^{2}$ and Joy B. Zedler ${ }^{1}$ \\ ${ }^{1}$ Department of Botany, University of Wisconsin, 430 Lincoln Dr., Madison, Wisconsin 53706 USA \\ ${ }^{2}$ Department of Environmental Studies, University of San Francisco, 2130 Fulton St., San Francisco, California 94117 USA
}

\begin{abstract}
The central tenet of biodiversity-ecosystem function (BEF) theory, that species richness increases function, could motivate restoration practitioners to incorporate a greater number of species into their projects. But it is not yet clear how well BEF theory predicts outcomes of restoration, because it has been developed through tests involving short-run and tightly controlled (e.g., weeded) experiments. Thus, we resampled our 1997 BEF experiment in a restored salt marsh to test for long-term effects of species richness (plantings with 1, 3, and 6 species per $2 \times 2 \mathrm{~m}$ plot), with multiple ecosystem functions as response variables. Over 11 years, 1 - and 6-species assemblages converged on intermediate richness (mean $=3.9$ species/ $0.25-\mathrm{m}^{2}$ plot), and composition changed nonrandomly throughout the site. While three species became rare, the two most productive species became co-dominant. The two dominants controlled and increased shoot biomass, which appeared to decrease species richness. Diversity-function relationships became less positive over 11 years and differed significantly with (a) the species-richness metric (planted vs. measured), and (b) the indicator of function (shoot biomass, height, and canopy layering). The loss of positive relationships between species richness and function in our restored site began soon after we stopped weeding and continued with increasing dominance by productive species. Where species-rich plantings are unlikely to ensure long-term restoration of functions, as in our salt marsh, we recommend dual efforts to establish (1) dominant species that provide high levels of target functions, and (2) subordinate species, which might provide additional functions under current or future conditions.
\end{abstract}

Key words: BEF theory; biodiversity; competitive exclusion; diversity-productivity; ecosystem function; long-term restoration; Salicornia virginica; salt marsh; species richness.

\section{INTRODUCTION}

In restoration ecology, a widely published conceptual model shows ecosystem function increasing linearly with community structure or species diversity (e.g., Bradshaw 1984, 2002). Independently, ecologists (notably, Tilman 1999) showed that biodiversity and ecosystem function (hereafter, BEF) were positively related, and confirmation by dozens of controlled experiments led to BEF theory (Hooper et al. 2005, Schmid et al. 2009). In practice, however, few restorationists have capitalized on opportunities to manipulate species richness to increase target functions at substantial spatial and temporal scales (Naeem 2006, Wagner et al. 2008, Wright et al. 2009; but see Bullock et al. 2001, 2007). Without realistic field tests, a key question remains unanswered: Can restoration practitioners increase levels of target functions by planting more species?

Most BEF experiments have used synthetic communities, i.e., assemblages of randomly drawn species set up in controlled or homogenized environments; they have

Manuscript received 3 August 2010; revised 10 February 2011; accepted 22 February 2011. Corresponding Editor: J. S. Baron.

${ }^{3}$ E-mail: jdohert1@gmail.com been weeded regularly and grown for short time periods $(<5$ years [Cardinale et al. 2007]). As a result, many ecologists have questioned the broader applicability of BEF theory (Wardle 1999, Srivastava and Vellend 2005, Thompson et al. 2005, Thompson and Starzomski 2007, Jiang et al. 2009, Wardle and Jonsson 2010). Recent experiments addressed criticisms by incorporating natural community structure (Wilsey and Polley 2004, Zavaleta and Hulvey 2004, Bracken et al. 2008), variable environmental conditions (Tylianakis et al. 2008, Romanuk et al. 2009), unweeded plantings (Pfisterer et al. 2004, Roscher et al. 2009), and long time periods (Tilman et al. 2006, van Ruijven and Berendse 2009). Still, no one has shown that the species richness of plantings directly increases long-term functional benefits in ecologically restored sites (i.e., without weeding and replanting).

Researchers weed and replant plots in order to attribute functional outcomes to species richness rather than the loss or gain of any particular species (Tilman 1999). In grassland experiments, weeding extended the persistence of positive diversity-productivity relationships to eight or more years (Tilman et al. 2006, van Ruijven and Berendse 2009), while unweeded counterparts lost similar relationships in just two years (Pfisterer 
et al. 2004, Roscher et al. 2009). In restored and natural plant communities, however, species loss and gain are nonrandom (Grime 1998, Wardle 1999, Pywell et al. 2003), and changes in composition can be more important to ecosystem function than changes in richness per se (Hooper and Vitousek 1997, Tilman et al. 1997, Solan et al. 2004, Zavaleta and Hulvey et al. 2007, Bracken et al. 2008). Recent experiments and simulations suggest that ecosystem function is little affected when low-function species are lost nonrandomly, but it decreases markedly when high-function species are lost nonrandomly (Smith and Knapp 2003, Schlapfer et al. 2005, Duffy et al. 2009). As restored plant communities mature, their BEF relationships could be affected by trait-based changes in composition and abundance that are lacking in short-term weeded experiments.

In long-term field experiments, diversity and productivity could exhibit feedbacks that would complicate BEF relationships. However, Cardinale et al. (2007) predicted that BEF relationships would become increasingly positive as interspecific interactions and complementarity develop over time. While their prediction was based on experimental evidence, Guo (2003) used data on natural plant succession to predict the opposite, that BEF relationships would shift from positive to neutral to negative over time. Under Guo's prediction, competition and competitive exclusion lead to areas of high productivity and low diversity as a community matures, an idea supported by negative BEF relationships (i.e., decreasing productivity with increasing richness) observed in natural grasslands (Thompson et al. 2005, Grace et al. 2007). Such competitive interactions might be unable to develop in short-term BEF experiments, especially if weeding moderates competition (Jiang et al. 2009).

In addition, extending BEF theory to restoration requires that researchers evaluate functions that are important to the practice. Examples of such functions include ground cover and canopy height, which are used to evaluate wildlife support (Palmer and Filoso 2009). Such "stock-type" functions or structural attributes are more familiar to restorationists and are less costly and less destructive to sample than productivity, which is the most commonly measured function in BEF experiments (Shrivastava and Vellend 2005). Stock-type functions generally respond more strongly and more positively to species richness than "flux-type" functions (i.e., processes [Schmid et al. 2009]), and their responses to species richness might differ from that of productivity. Researchers are thus advised to measure multiple functions to characterize ecosystem responses (Hector and Bagchi 2007, Gamfeldt et al. 2008, Zavaleta et al. 2010).

Strong tests of BEF relationships in restoration sites would follow multiple stock-type indicators of interest to practitioners in unweeded field experiments for time periods that allow the vegetation to mature. Our 1997 field experiment (plantings of $0,1,3$, and 6 species) to restore a tidal marsh in southern California offered such an opportunity. In natural, relatively undisturbed Californian salt marshes, eight species are typically present with high evenness (Zedler and West 2008). Plant height is an indicator of bird use, because the state-endangered Belding's Savannah Sparrow (Passerculus sandwichensis beldingi) perches on the tallest marsh-plain plants to establish and defend its nesting territory. Canopy layering is an indicator of camouflage and use by arthropods and small mammals during low tide. Biomass can be a proxy for multiple functions depending on how it is assessed. Total shoot biomass indicates late-summer camouflage for resident and migratory birds; green shoot biomass (fresh leaf material) is an indicator of herbivore food stocks; and brown shoot biomass (accumulated stem material) is an indicator of overwinter camouflage and also structural rigidity, another component of the bird-perching function.

During the first three growing seasons (1997-2000), with weeding only through October 1998, species richness increased eight response variables (shoot biomass, root biomass, soil nitrogen accumulation, plant cover, mean canopy height, maximum canopy height, canopy layering, and resistance to invasion [Keer and Zedler 2002, Lindig-Cisneros and Zedler 2002, Callaway et al. 2003]). A parallel greenhouse experiment (Sullivan et al. 2007) showed similar positive BEF relationships, and, based on eightfold replication of the 32 assemblages and eight monotypes planted in our field site, we attributed the positive BEF relationships to selection effects. That is, two highly productive species, Salicornia virginica (Sv) and Jaumea carnosa (Jc), dominated assemblages and increased productivity in high-richness treatments because they were planted there more frequently (an artifact of experimental design). These early analyses, along with additional field studies and experimentation (Bonin and Zedler 2008, Varty and Zedler 2008, Zedler and West 2008; H. N. MorzariaLuna and J. B. Zedler, unpublished manuscript) helped us interpret later changes in structure and function.

Because composition and dominance were clearly changing over time (Zedler and West 2008), we anticipated changes in BEF relationships. We hypothesized that (1) relationships between species richness and indicators of ecosystem function would change in response to the observed shifts in composition, (2) productive dominants would lower species richness, (3) BEF relationships would become less positive over time, and (4) those relationships would vary with the species richness metric (planted vs. measured) and the indicator of function (maximum canopy height, canopy layering, total shoot biomass, green shoot biomass, and brown shoot biomass).

\section{Materials and Methods}

\section{Site description and experimental setup}

The Tidal Linkage is a 0.7-ha site in the northern arm of the Tijuana River National Estuarine Research Reserve $\left(32.574^{\circ} \mathrm{N}, 117.126^{\circ} \mathrm{W}\right)$, hereafter Tijuana Estuary. It has 


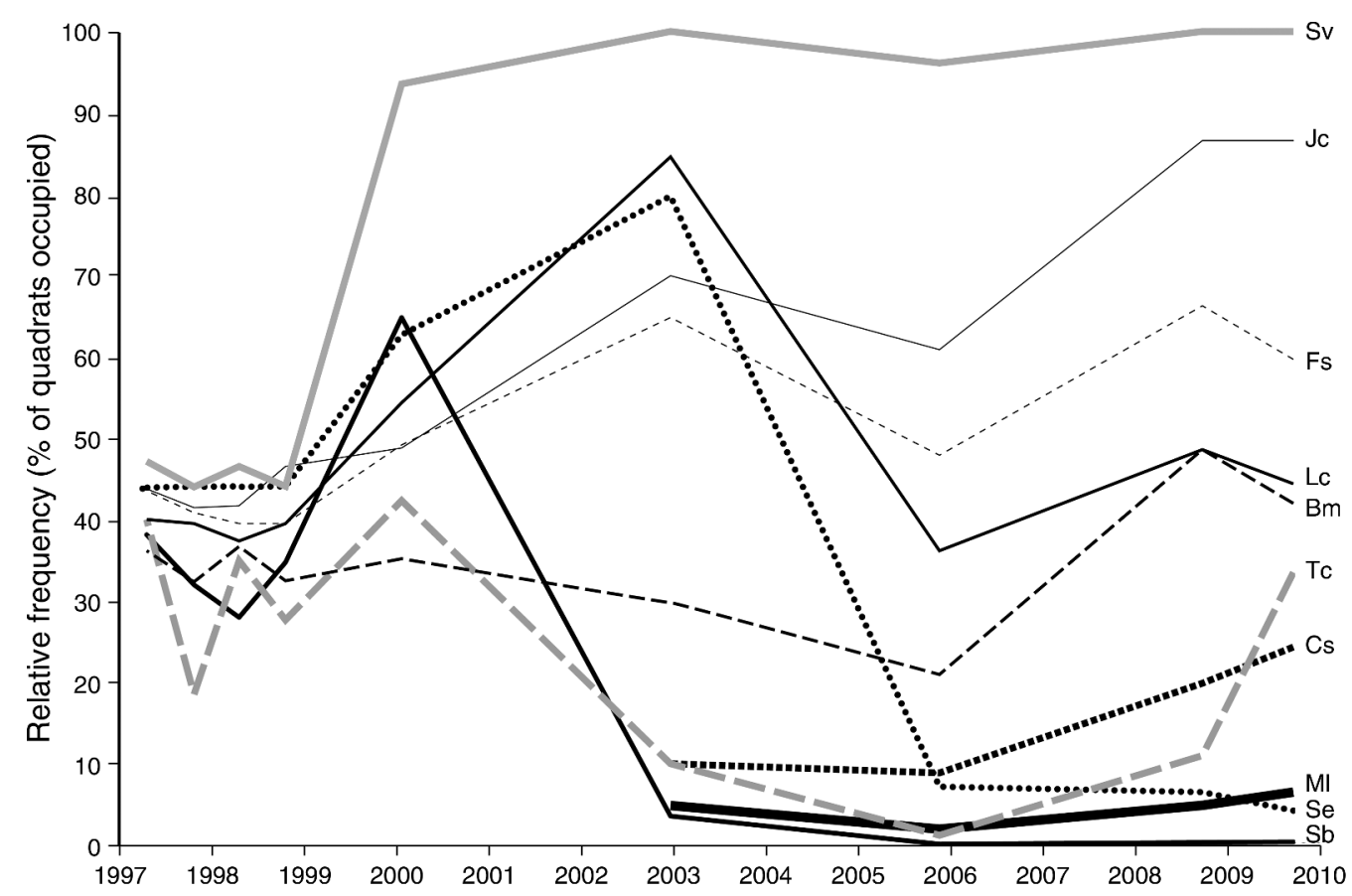

FIG. 1. Frequency of each salt marsh plant species during our 12 years of sampling in the Tiajuana Estuary, southern California, USA. Abbreviations are as follows: Batis maritima (Bm), Frankenia salina (Fs), Jaumea carnosa (Jc), Limonium californicum (Lc), Salicornia bigelovii (Sb), Suaeda esteroa (Se), Salicornia virginica (syn. Sarcocornia pacifica) (Sv), Triglochin concinna (Tc), Monanthochloe littoralis (Ml), and Cuscuta salina (Cs). Ml and Cs were not planted but had self-recruited by December 2002. Data from April 1997 represent planted frequencies within our 45 focal plots; data from October 1997, April 1998, and October 1998 come from 1.2-m transects sampled within 43 of the focal plots; data from January 2000, September 2008, and September 2009 data come from $0.25-\mathrm{m}^{2}$ quadrats sampled within the 45 focal plots; and data from December 2002 and November 2005 come from $0.25-\mathrm{m}^{2}$ monitoring quadrats sampled at random points within the site $(n=20$ and 101 , respectively).

a central tidal channel and two adjacent tidal plains, all excavated from disturbed upland in 1996 to connect a natural tidal channel to a tidal lagoon. The south tidal plain was planted to test BEF theory (Keer and Zedler 2002 ) as follows. In April of 1997, we established $872 \times 2$ $\mathrm{m}$ experimental plots with assemblages of 0,1 (solos), 3 (trios), or 6 (sextets) native salt marsh plant species drawn from the eight native species that are common to the marsh plain of Tijuana Estuary and were known to cooccur at small spatial scales (often in $0.25-\mathrm{m}^{2}$ monitoring quadrats). These treatments are referred to as "planted species richness." The eight planted species were: Batis maritima $(\mathrm{Bm})$, Frankenia salina $(\mathrm{Fs})$, Jaumea carnosa $(\mathrm{Jc})$, Limonium californicum $(\mathrm{Lc})$, Salicornia bigelovii $(\mathrm{Sb})$, Suaeda esteroa (Se), Salicornia virginica (syn. Sarcocornia pacifica) (Sv), and Triglochin concinna (Tc). Assemblages were drawn at random to avoid confounding composition and species richness (Tilman 1999).

All seedlings were grown from Tijuana Estuary seed for five months in greenhouse flats before planting (Keer and Zedler 2002), and each $2 \times 2 \mathrm{~m}$ plot was planted with exactly 90 seedlings to avoid selection effects arising from differential establishment (Huston 1997). Because our assemblages were randomly chosen, the total number or seedlings planted varied slightly from species to species $($ low $=755$, high $=885$; Fig. 1$)$. Nearly all seedlings survived (Callaway et al. 2003). Treatments were replicated within five experimental blocks along the south marsh plain (each block had three trios, three sextets, and all eight solos). The absolute elevation of each plot was measured in 1997 using a surveyor-grade auto-level. Composition and planted species richness were maintained for 18 months after planting by weeding unplanted recruits and, rarely, by replacing dead seedlings. Thereafter, recruits were allowed to establish in all plots. Monanthochloe littoralis (Ml) and Cuscuta salina (Cs) were not planted but had recruited by 2002 (Zedler and West 2008).

\section{Sampling ecosystem structure and functions}

In October 1997, April 1998, and October 1998, Keer and Zedler (2002) measured maximum height and canopy layering (the number of points of contact by a pin dropped vertically through the canopy) along $1.2-\mathrm{m}$ transects in the $2 \times 2 \mathrm{~m}$ plots to characterize the development of canopy architecture. We used data from those 1.2-m transects as our "measured species richness" for the 1997-1998 sampling periods. In January 2000, Callaway et al. (2003) sampled shoot biomass within a rectangular $0.24-\mathrm{m}^{2}$ frame by clipping all shoot biomass to ground level. Shoot biomass was sorted by species, dried, and weighed. The number of species that 
contributed shoot biomass in each plot is our "measured species richness" for January 2000.

In September 2008, Doherty resampled 15 solos, 15 trios, and 15 sextets of the original 87 plots established at the Tidal Linkage. In order to obtain balanced data that included the treatments most relevant to testing our planted treatments, we sampled a random subset of the solos, trios, and sextets, leaving out the 15 unplanted plots, 25 solos, one trio, and one sextet. Composition, species richness, maximum height, canopy layering, and shoot biomass were sampled within circular $0.25-\mathrm{m}^{2}$ quadrats following the methods of Keer and Zedler (2002) and Callaway et al. (2003). In addition, shoot biomass was separated into "green" shoot biomass and "brown" shoot biomass following Onuf and Quammen (1987) and Pennings and Callaway (1992). In September 2009, Doherty returned to the same 45 plots and resampled the $0.25-\mathrm{m}^{2}$ areas where aboveground biomass had been removed in September 2008. He sampled composition, species richness, maximum height, canopy layering, and aboveground biomass, which was now equivalent to green biomass, since all accumulated biomass had been clipped and removed in September 2008.

\section{Analysis}

We compared 43 plots sampled by Doherty in September 2008 and September 2009 to the same plots sampled by Keer and Zedler (2002) in 1997 and 1998 (15 solos, 14 trios, and 14 sextets) and 45 plots Callaway et al. (2003) in January 2000 (15 solos, 15 trios, and 15 sextets). The unequal replication in our resample of Keer and Zedler's plots occurred because one trio and one sextet did not coincide with the 45 sampled by Callaway et al. (2003). Thus, we compare and present data only from the 43 or 45 plots that were originally sampled by Keer and Zedler or Callaway et al., respectively.

We calculated several indices related to changes in community structure, including the Jaccard similarity index between composition of original plantings vs. sampled composition in October 1997, April 1998, October 1998, January 2000, September 2008, and September 2009. To objectively identify dominant species we calculated the species dominance index (SDI), an importance value that includes a species' mean abundance, tendency to achieve top abundance, and tendency to suppress other species (developed in Frieswyk et al. 2007); a species with above-average SDI is considered dominant. We also used the proportional biomass of individual species $\left(p_{i}\right)$ and measured species richness $(S)$ to derive: Simpson's diversity $\left(1 /\left[\Sigma p_{i}^{2}\right]\right)$, Simpson's evenness $\left(1 /\left[\Sigma p_{i}^{2}\right] / \mathrm{S}\right)$, and Berger-Parker dominance (maximum $p_{i}$ ) for all five biomass parameters (2000 total shoot biomass, 2008 total, green, and brown shoot biomass, and 2009 green biomass) on the basis of species'quadrat-scale $p_{i}$ and on their site-scale $p_{i}$ (i.e., based on cumulative biomass at each sampling period).

We analyzed all relationships between species richness (planted or measured) and response variables with linear regressions using the $\mathrm{R}$ statistical package ( $\mathrm{R}$ Development Core Team 2008). We also used linear regressions to assess the influence of several individual parameters (planted richness, measured richness, Simpson's diversity and evenness, Berger-Parker dominance, elevation, experimental block, and species planted/unplanted in 1997 (yes or no, for each species)) on biomass parameters that were significantly correlated to planted or measured richness. Supporting trends were analyzed with $t$ tests, simple linear regressions, and oneway ANOVAs.

\section{Results}

\section{Changes in structure and function}

As the site matured, $\mathrm{Sb}, \mathrm{Se}$, and Tc became rare, Fs, $\mathrm{Lc}$, and $\mathrm{Bm}$ remained common, and $\mathrm{Sv}$ and $\mathrm{Jc}$ became very frequent (Fig. 1). (See Materials and Methods: Site description and experimental setup for species abbreviations.) The loss and gain of species shifted composition and species richness substantially (Table 1), and the correlation between planted and measured species richness broke down over time (Fig. 2). Early changes in composition and richness were driven by colonization. The top colonizers (thousands of seedlings in 1997 and 1998 documented by Lindig-Cisneros and Zedler 2002) were Sv (clonal-perennial), Sb (annual), and Se (short-lived perennial). In January 2000, just 32 months after planting, three species were the most frequent (ranking $\mathrm{Sv}>\mathrm{Sb}>\mathrm{Se}$ ) and accounted for the most unplanted biomass (ranking $\mathrm{Sb}>\mathrm{Sv}>\mathrm{Se}$ [Callaway et al. 2003]). Also, by January 2000, Sv, Sb, and Jc (clonalperennial) had become site dominants, according to the SDI. However, at the same time, species richness at the quadrat scale was at its maximum (4.5), as were sitescale levels of Simpson's evenness (0.48) and diversity (3.8), and Berger-Parker dominance was at its lowest (0.44; Table 1).

From January 2000 to September 2008, Sv changed from $93 \%$ to $100 \%$ frequency, and its contribution to community total shoot biomass changed from $44 \%$ to $52 \%$. At the same time, Jc changed from $49 \%$ to $86 \%$ frequency and its contribution to community total shoot biomass changed from $21 \%$ to $36 \%$ (Fig. 3). SDI showed that $\mathrm{Sv}$ and $\mathrm{Jc}$ were the only dominant species in September 2008 and 2009. In contrast, another early dominant, the annual Sb, was rare in December 2002 and absent in September 2008 and September 2009. Similarly, the short-lived Se was rare in November 2005 and remained in $<10 \%$ of plots thereafter. The one deciduous species, Tc, dropped in frequency at the same time, although it may have persisted belowground during December 2002 and November 2005 surveys when shoots were absent. Three perennial species, Bm, Fs, and Lc, maintained moderate frequencies but contributed far less shoot biomass than Sv and Jc in January 2000, September 2008, and September 2009 (Fig. 3). 
TABLE 1. Indicators of structure and function (mean, with SE in parentheses) measured within plots over time.

\begin{tabular}{|c|c|c|c|c|c|c|c|}
\hline \multirow{2}{*}{$\begin{array}{l}\text { Indicators of structure } \\
\text { and function }\end{array}$} & \multirow[b]{2}{*}{ Units } & \multicolumn{6}{|c|}{ Sampling date } \\
\hline & & Oct 1997 & Apr 1998 & Oct 1998 & Jan 2000 & Sep 2008 & Sep 2009 \\
\hline $\begin{array}{l}\text { Compositional similarity } \\
\text { to April } 1997 \text { plantings }\end{array}$ & (Jaccard, \%) & $94 \quad(2) \mathrm{a}$ & $87 \quad(3) \mathrm{a}$ & $94 \quad(2) \mathrm{a}$ & $58 \quad(4) b$ & $34 \quad(3) c$ & $35 \quad(3) \mathrm{c}$ \\
\hline Measured species richness & (no. species) & $3.0(0.3) \mathrm{a}$ & $3.1(0.3)$ & $3.1(0.3) \mathrm{a}$ & $4.5(0.2) b$ & $3.9(0.2) \mathrm{ab}$ & $4.0(0.3) \mathrm{ab}$ \\
\hline Planted biomass & (as $\%$ of all biomass) & & & & $84 \quad(4) \mathrm{a}$ & 49 (6)b & $51(6) \mathrm{b}$ \\
\hline $\begin{array}{l}\text { Dominant species (sensu } \\
\text { Frieswyk et al. 2007) }\end{array}$ & & & & & $\mathrm{Sv}, \mathrm{Jc}, \mathrm{Sb}$ & $\mathrm{Sv}, \mathrm{Jc}$ & $\mathrm{Sv}, \mathrm{Jc}$ \\
\hline Maximum height & $(\mathrm{cm})$ & $20 \quad(1.2) \mathrm{a}$ & $19 \quad(1.4) \mathrm{a}$ & $38 \quad(2.5) \mathrm{b}$ & & $37 \quad(1.2) \mathrm{b}$ & $33 \quad(1.2) \mathrm{b}$ \\
\hline Canopy layering & (no. hits/pin drop) & $1.9(0.1) \mathrm{a}$ & $2.0(0.1) \mathrm{a}$ & $2.7(0.2) \mathrm{b}$ & & $5.3(0.2) \mathrm{c}$ & $3.5(0.2) \mathrm{d}$ \\
\hline Total shoot biomass & $\left(\mathrm{g} / 0.25 \mathrm{~m}^{2}\right)$ & & & & $(8) \mathrm{a}$ & $210 \quad(10) b$ & \\
\hline Green shoot biomass & $\left(\mathrm{g} / 0.25 \mathrm{~m}^{2}\right)$ & & & & & (8)a & $(5) \mathrm{b}$ \\
\hline Brown shoot biomass & $\left(\mathrm{g} / 0.25 \mathrm{~m}^{2}\right)$ & & & & & (7) & \\
\hline
\end{tabular}

Notes: Lowercase letters indicate statistically different means by sampling date $(P<0.05$, determined by $t$ test for total and green shoot biomass, and ANOVA followed by Tukey contrasts for others). For October 1997, April 1998, and October 1998, $n=43$; for all others, $n=45$. See Fig. 1 for plant species codes.

Indicators of community function also changed over time. At 12 and 18 months after planting, Sv was the tallest species and $\mathrm{Jc}$ had the highest cover (using data of Keer and Zedler 2002). Sv was also responsible for the maximum height in $35 \%$ of plots 18 months after planting (January 2000), and in $91 \%$ of plots 11 years after planting (September 2008). Over time, Jc comprised a greater portion of total biomass, mostly as green biomass, and $\mathrm{Sv}$ added mostly brown biomass. Together, they contributed $63 \%$ of total shoot biomass (42\% Sv, 21\% Jc) in January 2000. Eight years later, in September 2008, they contributed $88 \%$ of total shoot biomass $(52 \% \mathrm{~Sv}, 36 \% \mathrm{Jc}), 87 \%$ of green shoot biomass $(53 \% \mathrm{~Sv}, 34 \% \mathrm{Jc}), 89 \%$ of brown shoot biomass $(82 \% \mathrm{~Sv}$, $7 \% \mathrm{Jc}$ ); and in 2009 , they made up $80 \%$ of green shoot biomass ( $40 \% \mathrm{~Sv}, 40 \% \mathrm{Jc})$.

With Sv and Jc dominant in September 2008, sitescale Simpson's evenness (0.31) and diversity (2.5) were low (the same for both total and green shoot biomass) and Berger-Parker dominance was high ( 0.52 for total shoot biomass and 0.53 for green shoot biomass). Also, September 2008 brown biomass, the vast majority of which was Sv, had minimal Simpson's evenness $(0.29)$ and diversity (1.5), and Berger-Parker dominance (0.82) was maximal. In September 2009, when Sv and Jc made up $80 \%$ of green shoot biomass (and did so equally), Simpson's evenness (0.37) and diversity (3.0) increased, and Berger-Parker dominance decreased (0.40).

Site means of all response variables increased over time, but on unique trajectories. Maximum height increased during the second growing season (April 1998 to October 1998), then did not change in 2008 or 2009 (Table 1). Canopy layering also increased significantly over the second growing season, increased again by September 2008, but fell slightly by September 2009 (Table 1). Total shoot biomass increased from January 2000 to September 2008, but green shoot biomass decreased from September 2008 to September 2009 (Table 1).

\section{Changes in BEF relationships}

BEF relationships in our site differed with time of assessment, species richness metric, and the response variable. Formerly positive BEF relationships showed no significant correlation in our later data, as follows. Planted and measured species richness increased maximum height and canopy layering in April 1998 but had no significant effect on either response variable in

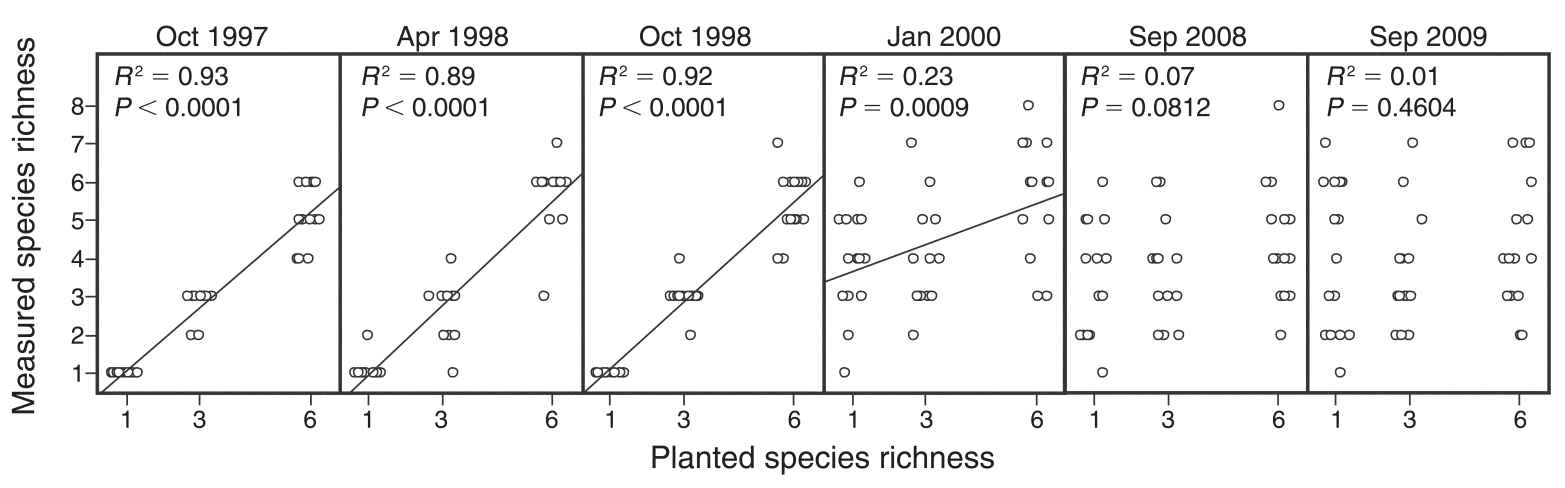

FIG. 2. Measured vs. planted species richness (no. species) during our 12 years of sampling. Trend lines are drawn only for statistically significant regressions $(P<0.05)$ as shown by $R^{2}$ and $P$ values. For October 1997-October $1998, n=43$, and for all other dates $n=45$ focal plots. 

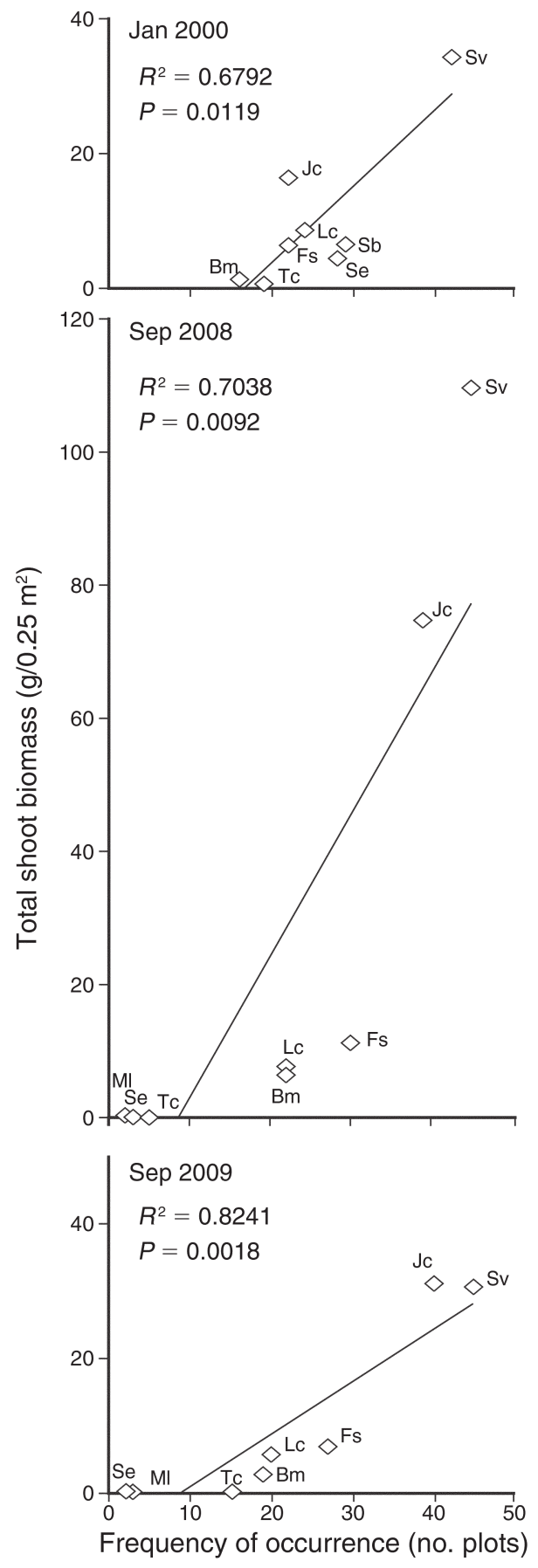

FIG. 3. Mean "total shoot biomass" of each species (calculated as the sum of material collected across the 45 sampled plots divided by the number of plots sampled [45]; total shoot biomass was equal to green shoot biomass in September 2009 ) vs. the number of plots occupied by the same species, in January 2000, September 2008, and September 2009. Significant correlations are indicated with trend lines as shown by $R^{2}$ and $P$ values. Data for each regression are from the same 45 plots. Species codes are as in Fig. 1.
September 2008 or September 2009 (Fig. 4A, B), planted richness increased total shoot biomass in January 2000 but had no significant effect in September 2008, and planted shoot biomass increased green shoot biomass in September 2008 but not September 2009 (Fig. 5).

Some BEF relationships varied by species richness metric. Canopy layering in October 1998 (just after weeding ceased) increased with measured richness but not planted richness, total shoot biomass in January 2000 and green shoot biomass in September 2008 both increased with planted richness but not measured species richness, and total shoot biomass in September 2008 decreased with measured richness but not planted richness.

Even related response variables caused some BEF relationships to differ. In September 2008 planted species richness increased green shoot biomass but decreased brown shoot biomass. And in September 2008, while total and brown shoot biomass were both negatively correlated to measured species richness and green biomass was positively correlated with planted richness, all other indicators of function were random in relation to species richness.

Planted and measured species richness were not the only factors influencing shoot biomass parameters in January 2000 and September 2008 (Table 2). A block effect influenced January 2000 total shoot biomass and September 2008 green biomass, while elevation (vertical range of $<0.4 \mathrm{~m}$ ) influenced September 2008 total shoot biomass. For 2008 brown shoot biomass, Berger-Parker dominance was the best single predictor. Simpson's evenness at the quadrat scale was not a significant predictor for any biomass parameter, and like measured species richness, Simpson's diversity was negatively correlated with 2008 total shoot biomass and 2008 brown shoot biomass. Planted species richness was positively correlated with biomass parameters only when the planting of "influential" species was positively correlated with the same parameters (influential species being Sv and Se for January 2000 shoot biomass and Sv and Jc for September 2008 green biomass). Our regression of the number of influential species planted $(0,1$, or 2$)$ from the pairs $\mathrm{Sv}-\mathrm{Se}$ and $\mathrm{Sv}-\mathrm{Jc}$ on January 2000 total shoot biomass $\left(R^{2}=0.22, P=0.0012\right)$ and September 2008 green shoot biomass $\left(R^{2}=0.24, P=\right.$ 0.0007 ), respectively, showed positive effects of planted influential-species richness.

\section{DisCUSSION}

Given a wealth of experimental evidence that speciesrich vegetation can increase ecosystem functioning, it is reasonable for practitioners to ask if the pattern holds in sites designed to restore both diversity and ecosystem services, as indicated by Bradshaw (1984, 2002), Naeem (2006), and Wright et al. (2009). But because nearly half the experimental tests of richness effects have failed to identify positive BEF relationships (Schmid et al. 2009), there is great uncertainty about how function will 
A
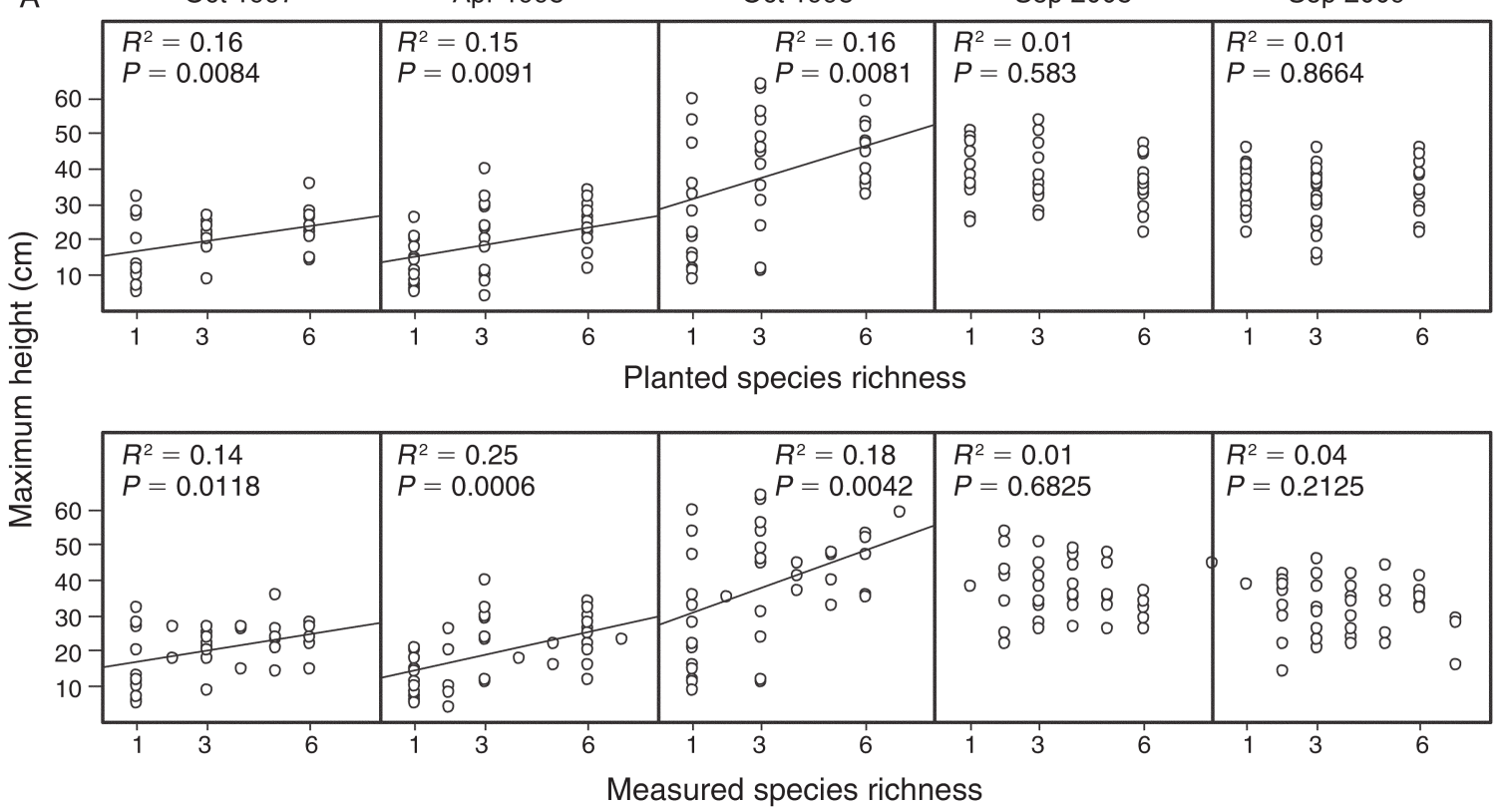

B

$\begin{array}{rrrr}\text { B } & \text { Oct } 1997 & \text { Apr } 1998 & \text { Oct } 1998\end{array}$

Sep 2008

Sep 2009

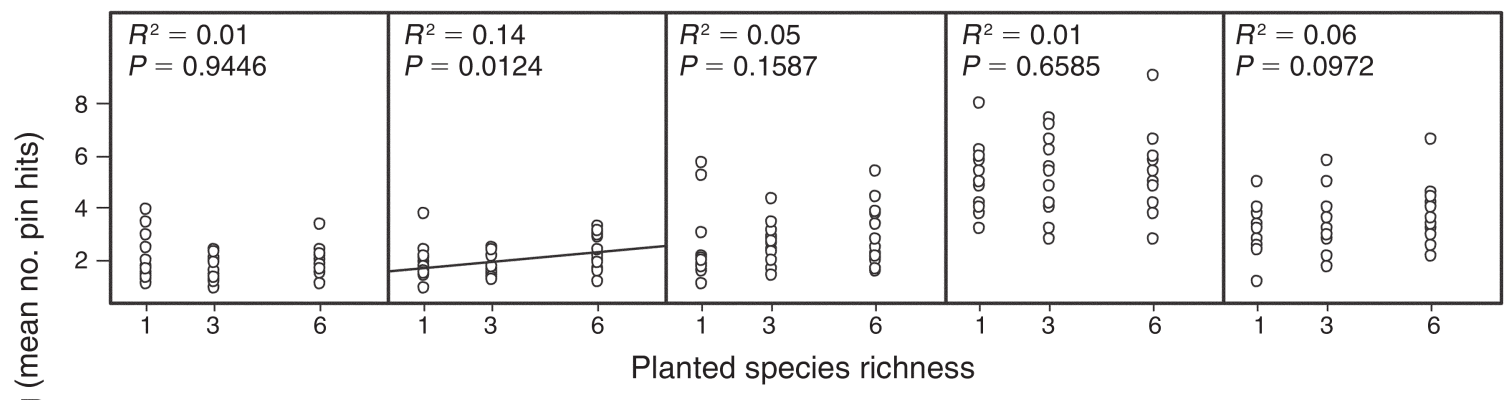

Planted species richness

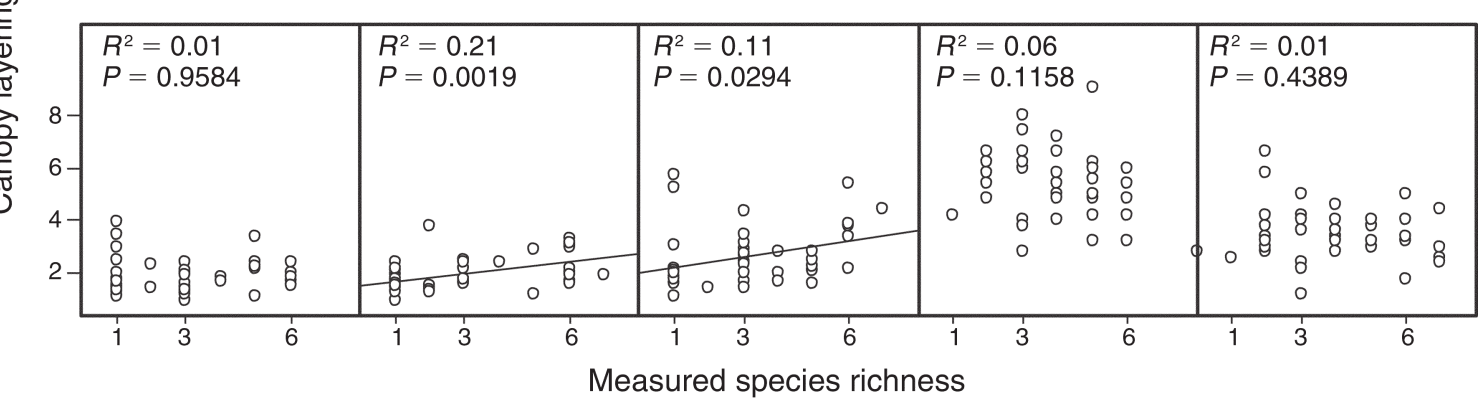

FIG. 4. (A) Maximum height vs. planted and measured species richness during our 12 years of sampling. The maximum height is the tallest leaf within each plot. (B) Canopy layering vs. planted and measured species richness during our 12 years of sampling. Canopy layering is the number of hits per pin dropped vertically through the canopy from $0.5 \mathrm{~m}$ height. Trend lines are drawn only for statistically significant regressions $(P<0.05)$ as shown by $R^{2}$ and $P$ values. Data for each regression come from the same 43 plots.

respond to diverse plantings in the long term and across a wide variety of restoration sites, many of which are in highly disturbed landscapes.

Our salt marsh study is unique as a true BEF experiment that matured as an unmanaged restoration site, and our results show that effects of planted richness were outweighed by effects of dominant species in the long term. In the first three growing seasons, increased salt marsh species richness led to increased maximum height, canopy layering, total shoot biomass, and five other indicators of ecosystem function (as listed previously [Keer and Zedler 2002, Lindig-Cisneros and 

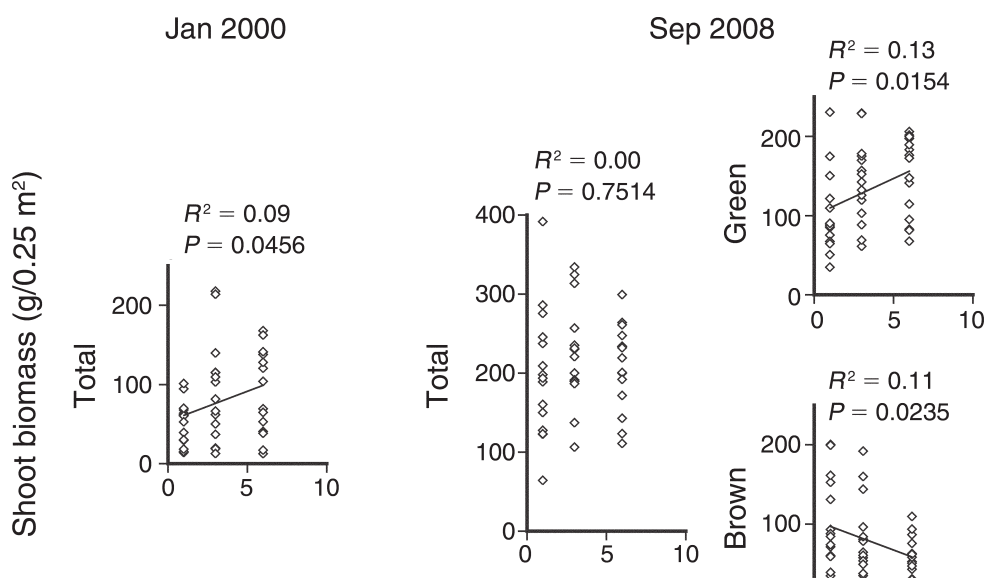

\section{Sep 2009}
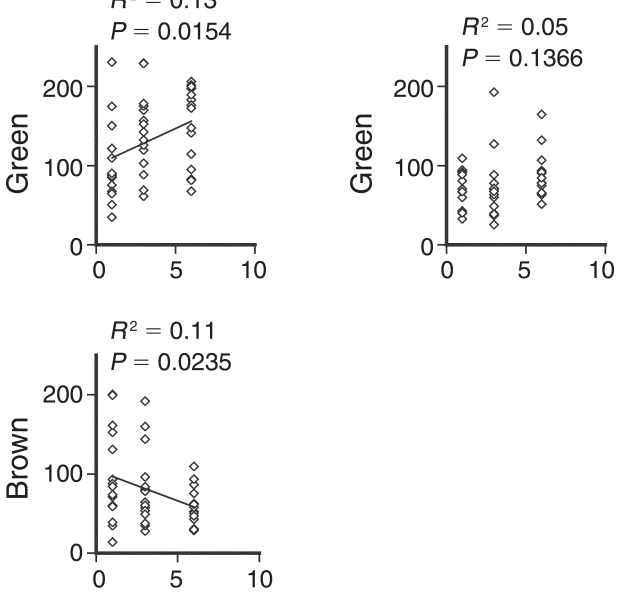

Planted species richness

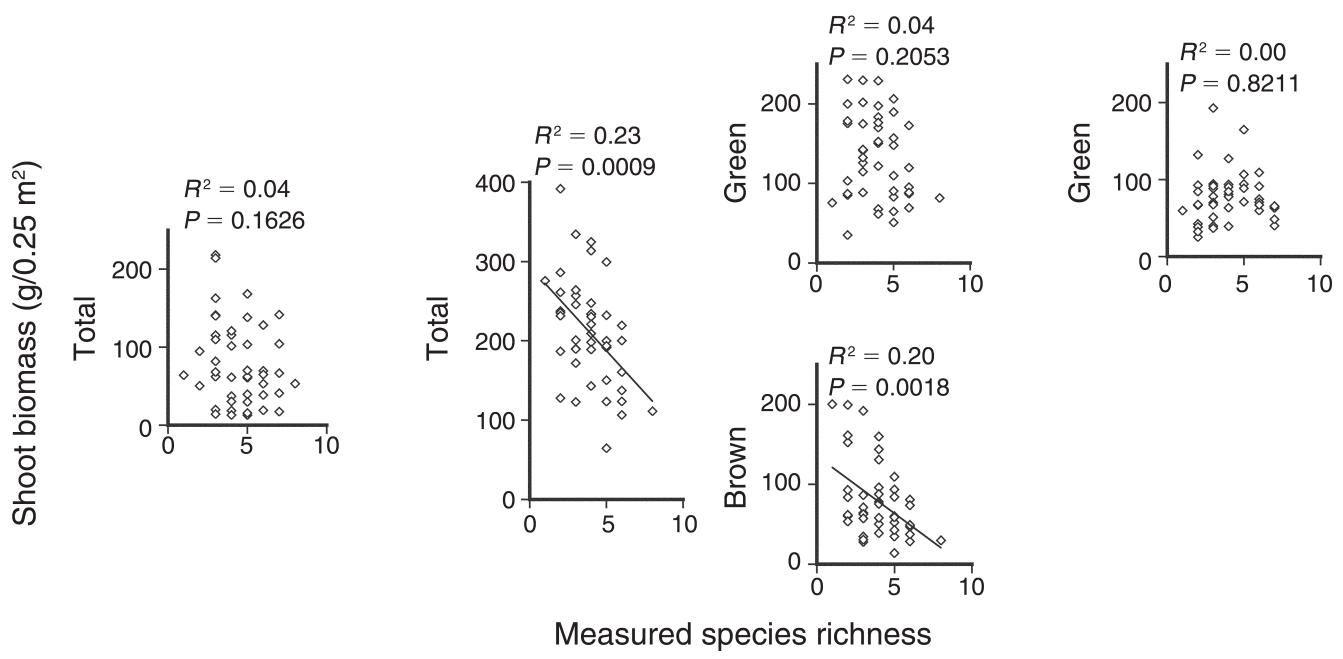

FIG. 5. Shoot biomass (total, green, or brown) vs. both planted and measured species richness during our 12 years of sampling. Trend lines are drawn only for statistically significant regressions $(P<0.05)$ as shown by $R^{2}$ and $P$ values. Data for each regression come from the same 45 plots.

Zedler 2002, Callaway et al. 2003]). In just 14 months without weeding (November 1998 to January 2000), Sv and Jc became dominants, and they continued to increase in frequency and abundance in the years that followed (Bonin and Zedler 2008, Zedler and West 2008). In contrast, three species, each with unique functional traits, decreased in frequency and abundance. The only annual, $\mathrm{Sb}$, was a highly productive colonizer (Lindig-Cisneros and Zedler 2002, Callaway et al. 2003), Se was short lived and was often the tallest species (Keer and Zedler 2002), and Tc was the only deciduous species and a notable sequesterer of soil nitrogen (Sullivan and Zedler 1999, Sullivan et al. 2007; H. N. Morzaria-Luna and J. B. Zedler, unpublished manuscript). The concurrent increase in $\mathrm{Sv}$ and $\mathrm{Jc}$ and decrease in $\mathrm{Sb}, \mathrm{Se}$, and $\mathrm{Tc}$ homogenized community structure among plots that were highly differentiated when planted (see Plate 1).
In 2008, our reassessment showed that the positive BEF relationships between planted species richness and maximum height, canopy layering, or total shoot biomass were gone. The BEF relationships we did find were sometimes negative and generally changed in sign or significance according to species richness metric (planted vs. measured) and function (e.g., brown vs. green shoot biomass). Our experimental salt marsh community shifted from artificially high evenness to strong dominance, which had the effect of simplifying canopy structure and increasing shoot biomass to levels that constrained local diversity.

\section{Dominance effects outweighed diversity effects}

Plots within our study site lost and gained species nonrandomly. They lost the less-productive and shortlived species ( $\mathrm{Sb}, \mathrm{Se}$, and $\mathrm{Tc}$ ) and gained highly 
productive clonal-perennials ( $\mathrm{Sv}$ and Jc; Fig. 1), which contributed the bulk of shoot biomass $(\geq 80 \%)$ by September 2008 and September 2009. Field and greenhouse monocultures showed that $\mathrm{Sv}$ and $\mathrm{Jc}$ produced the most shoot biomass of our eight planted species (Callaway et al. 2003, Sullivan et al. 2007). Thus, trait-based changes in composition transformed our experimental plots from randomly assigned assemblages to assemblages with productive dominants that were either tall (Sv) or produced long, trailing shoots ( Jc [Bonin and Zedler 2008]).

Our experiment counters a common criticism of BEF experiments, namely, that they simulate random species loss, a process seldom observed in nature (Wardle 1999, Shrivastava and Vellend 2005, Jiang et al. 2009). Two BEF experiments that employed realistic experimental communities showed more positive richness effects with nonrandom species addition, explained by having a natural dominant that was low functioning so that species addition boosted function (Bracken et al. 2008, Isbell et al. 2008). Likewise, where species with key functional roles were at high risk of loss, functioning increased with richness (Zavaleta and Hulvey 2004, 2007, Larsen et al. 2005). In other experiments where dominant, high-functioning species were unlikely to be lost, the outcome was different. That is, species loss had little effect on community processes (Smith and Knapp 2003, Solan et al. 2004, Schlapfer et al. 2005). Thus, when inherently high levels of a certain function (e.g., productivity) make species less susceptible to loss, we envisage little effect on community levels of that function when susceptible species are lost (Duffy et al. 2009). In most plant communities, less-productive species are more likely to be lost (Grime 1998, Wardle 1999, Pywell et al. 2003, Schlapfer et al. 2005). In a grassland experiment, Smith and Knapp (2003) found that more-productive species could compensate for the preferential loss of less-productive species, but compensation did not occur in the reverse scenario. In our salt marsh experiment, any decrease in productivity from losing short-lived and less-productive species appeared to be compensated by increased growth of Sv and Jc.

Based on our parallel greenhouse experiment (Sullivan et al. 2007), it appears likely that positive selection effects associated with Sv, and not complementarity effects, drove early positive BEF relationships at our site (Keer and Zedler 2002, Callaway et al. 2003). Plots planted with $\mathrm{Sv}$ and with more species-rich assemblages showed higher levels of total shoot biomass in January 2000 and green shoot biomass in September 2008, but planting of Sv was more strongly correlated with both biomass parameters than was planted richness (Table 2). Planting of other species also increased biomass parameters. In January 2000, plots planted with Sv (in 1997) increased total shoot biomass 73\%, and those planted with Se increased it 55\%, compared to plots where those species were not planted. Similarly, in September 2008, plots planted with Sv increased green
TABLE 2. Individual predictors of 2000 total shoot biomass and 2008 total, green, and brown shoot biomass.

\begin{tabular}{|c|c|c|}
\hline $\begin{array}{l}\text { Predictor, by year and } \\
\text { biomass parameter }\end{array}$ & Adjusted $R^{2}$ & $P$ \\
\hline \multicolumn{3}{|l|}{2000 , total shoot biomass } \\
\hline Block & \pm 0.41 & $<0.0001$ \\
\hline Sv planted & +0.15 & 0.0056 \\
\hline Se planted & +0.09 & 0.0262 \\
\hline Planted richness & +0.07 & 0.0455 \\
\hline \multicolumn{3}{|l|}{2008 , total shoot biomass } \\
\hline Elevation & -0.27 & 0.0002 \\
\hline Block & \pm 0.27 & 0.0020 \\
\hline Measured richness & -0.21 & 0.0009 \\
\hline Simpson's diversity & -0.19 & 0.0015 \\
\hline Berger-Parker dominance & +0.11 & 0.0140 \\
\hline \multicolumn{3}{|l|}{ 2008, green shoot biomass } \\
\hline Block & \pm 0.22 & 0.0066 \\
\hline Sv planted & +0.15 & 0.0048 \\
\hline Planted richness & +0.11 & 0.0154 \\
\hline Jc planted & +0.10 & 0.0166 \\
\hline \multicolumn{3}{|l|}{2008 , brown shoot biomass } \\
\hline Dominance (Berger-Parker's) & +0.51 & $<0.0001$ \\
\hline Diversity (Simpson’s) & -0.41 & $<0.0001$ \\
\hline Elevation & -0.19 & 0.0014 \\
\hline Measured richness & -0.19 & 0.0018 \\
\hline Sb planted & -0.14 & 0.0071 \\
\hline Planted richness & -0.09 & 0.0235 \\
\hline Jc planted & -0.09 & 0.0241 \\
\hline
\end{tabular}

Notes: Predictors tested as individual linear predictors for each biomass parameter include: planted richness, measured richness, Simpson's diversity and evenness, Berger-Parker dominance, elevation, experimental block, and whether or not each of the original eight species was planted in the plot (e.g., Sv planted indicates planting of Salicornia virginica). All statistically significant predictors $(P<0.05)$ are listed in descending order of adjusted $R^{2}$ with the direction of their effect $(+$ or - ) and $P$ value. See Fig. 1 legend for plant species codes.

shoot biomass $40 \%$, and plots planted with Jc increased it $33 \%$ compared to plots where those species were not planted. For the species affecting January 2000 total shoot biomass (Sv and Se) and September 2008 green shoot biomass ( $\mathrm{Sv}$ and $\mathrm{Jc}$ ), we found that plot biomass increased with the number of those species planted $(0,1$, or 2). However, as a whole, planted richness had little effect, and its positive correlation with biomass likely resulted from the effects of a small subset of species.

We attribute declines in plot-scale species richness and site-scale evenness to competitive exclusion by Sv and Jc. Shoot biomass of species was positively correlated with species' frequency of occurrence in January 2000, September 2008, and September 2009 (Fig. 3), a pattern that is consistent with competitive exclusion (Creed et al. 2009). By 2008 and 2009, plots with high shoot biomass often had Sv and Jc alone; plots with intermediate shoot biomass had Sv and Jc plus the fairly productive Fs, Bm, or Lc; and plots with low shoot biomass had all the above species plus the smaller and less common Se, Tc, Ml, or Cs. Sv probably excluded other species by growing tall through the accumulation of large perennial stems (brown biomass [Keer and Zedler 2002, Sullivan 

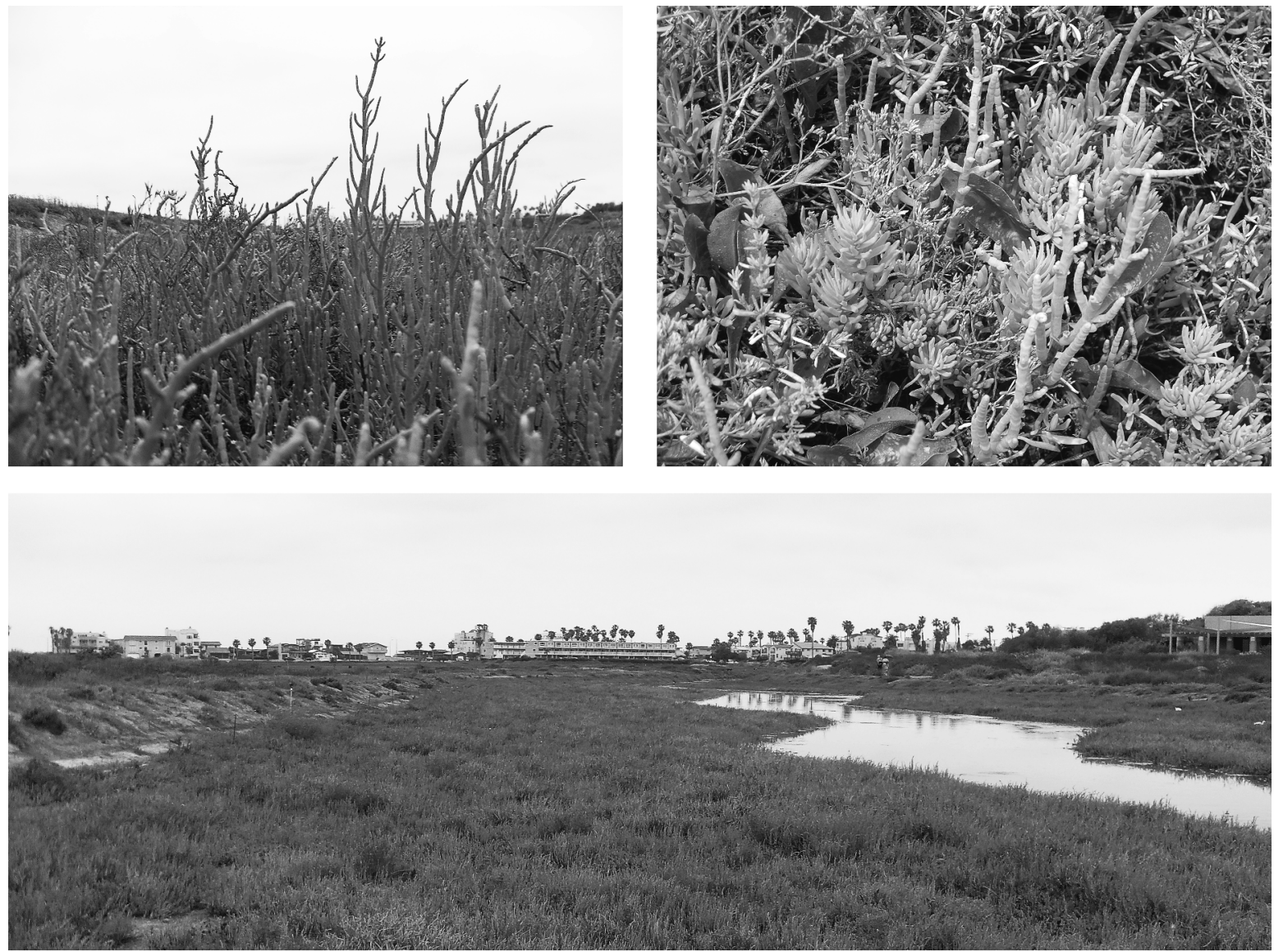

Plate 1. (Upper left) Tall shoots of the current dominant Salicornia virginica, (upper right) one of very few species-rich plots that remain from 1997 plantings, including the rare Suaeda esteroa with whorled leaves, and (lower panel) view of our salt marsh restoration 12 years after being planting as an experiment. Photo credits: J. M. Doherty.

et al. 2007, Bonin and Zedler et al. 2008]). In September 2008 , while Sv contributed the vast majority of brown biomass $(82 \%)$ and occupied every plot, plot levels of brown biomass increased as species' contributions became less equal (higher Berger-Parker dominance, lower Simpson's diversity). At the same time, high levels of brown shoot biomass and total shoot biomass likely decreased measured species richness (Table 2). We reason that over time competitive dominants $\mathrm{Sv}$ and Jc controlled and increased shoot biomass, decreased measured species richness, and gave rise to negative diversity-function relationships.

We are not the first to report negative BEF relationships. Creed et al. (2009) showed that leaf decomposition in streams was negatively related to caddisfly species richness because a single species was both functionally and competitively dominant. And in microbial and algal microcosms, BEF relationships became less positive over time because high-function, species-rich communities were the first to reach high density and experience growth limitation (Bell et al. 2005, Weis et al. 2007). Diversity also decreased in a BEF grassland experiment (Isbell et al. 2009), in restored grasslands (Sluis 2002, Camill et al. 2004), and in mature grasslands (Thompson et al. 2005, Grace et al. 2007) when highly productive species outcompeted neighbors.

\section{Diversity-function relationships were conditional}

BEF relationships changed over time in our site. Our findings do not support three predictions of Cardinale et al. (2007) that selection effects would gradually subside, complementarity effects would increase, and positive diversity-function relationships would strengthen over time. Although we conclude that positive diversityfunction relationships were selection driven and ephemeral, ours is one of very few long-term BEF field experiments and the only one in a restored salt marsh (Schmid et al. 2009). BEF experiments conducted in different systems and with various elements of ecological realism show different outcomes (Pfisterer et al. 2004, Schlapfer et al. 2005, Zavaleta and Hulvey 2007, Bracken et al. 2008; e.g., Romanuk 2009). Therefore, field tests of the planted richness effects in many more restored systems are needed to develop consensus and inform the practice of restoration. 
Many restored sites will experience disturbances that cause nonrandom changes in community composition that can affect BEF relationships. Our restoration site experienced minor disturbances of wrack deposition and herbivory as well as episodic flooding, nutrient influxes from runoff, and sedimentation. Except for the flood years of 1997 and 2003, the annual mean discharges of the Tijuana River were within $1 \mathrm{SD}$ of the grand mean for the 12-year study $\left(21.0 \times 10^{6} \pm 24.8 \times 10^{6} \mathrm{~m}^{3}\right.$ [mean $\pm \mathrm{SD}])$. The restored salt marsh responded to high sedimentation rates (relative to historic levels [Zedler 2010]), much like the adjacent natural salt marsh in the decades preceding our experiment: $\mathrm{Sv}$ and $\mathrm{Jc}$ also became increasingly dominant, and short-lived species were lost (Zedler and West 2008). Our experimental site offered a realistic test of BEF relationships specifically because it was a part of a dynamic estuary where increased flooding was altering habitat for endangered wildlife. The restoration project was undertaken and funded by state and federal agencies in order to offset losses of biodiversity and ecosystem functions in the adjacent salt marsh.

As in the natural marsh, species richness in our experiment gradually became a consequence of dominance rather than a driver of function. As a result, measured species richness diverged from planted species richness. Naturally, sextets lost species, and solos (which had low shoot biomass early in the experiment [Callaway et al. 2003]) were preferentially invaded (Lindig-Cisneros and Zedler 2002). Species richness converged toward the intermediate planting treatment, as reported in other unweeded BEF experiments (Pfisterer et al. 2004, Roscher et al. 2009). Because $\mathrm{BEF}$ relationships with measured vs. planted species richness differed in our data set, we recommend that researchers report both richness metrics.

Holding the richness metric constant, diversityfunction relationships differed with the indicator of function. In September 2008, planted species richness increased green shoot biomass and decreased brown shoot biomass. We reason that opposing trends were driven by unique functional contributions of our codominant species. Jc contributed the most green biomass of any species, and its green biomass alone was positively correlated with planted richness $\left(R^{2}=0.10\right.$, $P=0.0322$ ), whereas $\mathrm{Sv}$ contributed the most brown biomass of any species, and its brown biomass alone was negatively correlated with planted richness $\left(R^{2}=0.15, P\right.$ $=0.0083$ ). These patterns are likely explained by patterns of early recruitment. Jc typically invaded plots by vegetative spread, and its presence was still positively correlated with planted richness in $2000\left(R^{2}=0.24, P=\right.$ $0.0006)$, which was not the case for $\mathrm{Sv}\left(R^{2}=0.02, P=\right.$ $0.3944)$. Sv spread rapidly by seed, and after just 14 months without weeding it had colonized 21 new plots and occupied 42 out of 45 plots. The presence of Sv in all plots and Jc in 39 out of 45 plots by September 2008 and September 2009, and their high abundance in most plots, likely account for the homogenous levels of canopy layering and maximum height observed at those times. Given the varying BEF relationships across different indicators of ecosystem function, we emphasize the importance of assessing multiple indicators (Hector and Bagchi 2007, Gamfeldt et al. 2008, Zavaleta et al. 2010).

\section{Applications}

Planting long lists of species is warranted where high species richness is likely to increase target ecosystem functions, e.g., the restored grasslands studied by Bullock et al. (2001, 2007). As a precautionary measure, we suggest the same approach where the functional responses of restoration targets to diversity are not known (and funding is not limiting). Elsewhere, however, we recommend a dual strategy, in which practitioners would aim to restore function and diversity in different subareas or at different times.

In our California salt marsh, costly species-rich plantings have not persisted. While nearly all of the 6480 seedlings survived initially, the indicators of function that we assessed became uncoupled from species richness over time. And in a nearby 7-ha restoration site, $\sim 4000$ seedlings (of six species) died during extreme hypersalinity (Zedler et al. 2003), and most of the 540 replanted seedlings (five species) died within two years (O'Brien and Zedler 2006). Hence, we do not recommend planting all eight species simultaneously and in equal abundance across the marsh plain in future restoration efforts ( $>100$ ha). Similar setbacks occur in restorations of diverse tallgrass prairies, where the dominant Andropogon gerardii can exclude many planted species soon after site establishment (Sluis 2002, Camill et al. 2004).

In a dual strategy, the main or first planting would focus on target dominant species to accelerate development of cover and tall canopies, and the secondary planting would highlight establishment of a diverse community of subordinate species. However, target dominants that occur nearby, are readily dispersed, and colonize rapidly would not need to be planted. Such is the case for $\mathrm{Sv}$ in our California tidal marsh; we did not plant it in the 7-ha site, but it was a monotypic dominant by year 4 .

Early dominance could preclude establishment of subordinates, which might have special requirements for establishment or special functional traits. Hence, we recommend setting up a separate subarea or adding a second, later planting for target subordinates. If a subarea approach is used, it should be accessible for management purposes (e.g., weeding, controlled burning, etc.). If resources are not available to plant all species even in small areas, we suggest delaying introduction until suitable microsites become obvious for particular subordinate species (e.g., canopy gaps for sun species; canopies for shade tolerators). The dual approach would (1) establish productive dominants 
across most of the site, and (2) add subordinate species in smaller patches or at later dates. This approach is consistent with the precautionary principle, by maintaining subordinate species that may have functional traits that are not yet known or might be critical under future environmental conditions.

\section{ACKNOWLEDGMENTS}

Our research was supported by Earth Island Institute, the National Science Foundation (DEB 96-19875 to J. B. Zedler and J. C. Callaway), and a Garden Club of America Coastal Wetlands Scholarship to J. M. Doherty. The Tidal Linkage restoration project was funded by the U.S. Fish and Wildlife Service and the California State Coastal Conservancy. We thank the Tijuana River National Estuarine Research Reserve for encouraging long-term research.

\section{Literature Cited}

Bell, T., J. A. Newman, B. W. Silverman, S. L. Turner, and A. K. Lilley. 2005. The contribution of species richness and composition to bacterial services. Nature 436:1157-1160.

Bonin, C. L., and J. B. Zedler. 2008. Plant traits and plasticity help explain abundance ranks in a California salt marsh. Estuaries and Coasts 31:682-693.

Bracken, M. E. S., S. E. Friberg, C. A. Gonzalez-Dorantes, and S. L. Williams. 2008. Functional consequences of realistic biodiversity changes in a marine ecosystem. Proceedings of the National Academy of Sciences USA 105:924-928.

Bradshaw, A. D. 1984. Ecological principles and land reclamation practice. Landscape Planning 11:35-48.

Bradshaw, A. D. 2002. Introduction and philosophy. Pages 3-9 in M. R. Perrow and A. J. Davy, editors. Handbook of ecological restoration. Cambridge University Press, Cambridge, UK.

Bullock, J. M., R. F. Pywell, M. J. W. Burke, and K. J. Walker. 2001. Restoration of biodiversity enhances agricultural production. Ecology Letters 4:185-189.

Bullock, J. M., R. F. Pywell, and K. J. Walker. 2007. Longterm enhancement of agricultural production by restoration of biodiversity. Journal of Applied Ecology 44:6-12.

Callaway, J. C., G. Sullivan, and J. B. Zedler. 2003. Species-rich plantings increase biomass and nitrogen accumulation in a wetland restoration experiment. Ecological Applications 13:1626-1639.

Camill, P., M. J. McKone, S. T. Sturges, W. J. Severud, E. Ellis, J. Limmer, C. B. Martin, R. T. Navratil, A. J. Purdie, B. S. Sandel, S. Talukder, and A. Trout. 2004. Community- and ecosystem-level changes in a species-rich tallgrass prairie restoration. Ecological Applications 14:1680-1694.

Cardinale, B. J., J. P. Wright, M. W. Cadotte, I. T. Carroll, A. Hector, D. S. Srivastava, M. Loreau, and J. J. Weis. 2007. Impacts of plant diversity on biomass production increase through time because of species complementarity. Proceedings of the National Academy of Sciences USA 104:1812318128

Creed, R. P., R. P. Cherry, J. R. Pflaum, and C. J. Wood. 2009. Dominant species can produce a negative relationship between species diversity and ecosystem function. Oikos 118:723-732.

Duffy, J. E., et al. 2009. Forecasting decline in ecosystem services under realistic scenarios of extinction. Pages 60-77 in S. Naeem, D. Bunker, A. Hector, M. Loreau, and C. Perrings, editors. Biodiversity, ecosystem functioning, and human wellbeing: An ecological and economic perspective. Oxford University Press, Oxford, UK.

Frieswyk, C. B., C. A. Johnston, and J. B. Zedler. 2007. Identifying and characterizing dominant plants as an indicator of community condition. Journal of Great Lakes Research 33:125-135.
Gamfeldt, L., H. Hillebrand, and P. R. Jonsson. 2008. Multiple functions increase the importance of biodiversity for overall ecosystem functioning. Ecology 89:1223-1231.

Grace, J. B., et al. 2007. Does species diversity limit productivity in natural grassland communities? Ecology Letters 10:680-689.

Grime, J. P. 1998. Benefits of plant diversity to ecosystems: immediate, filter and founder effects. Journal of Ecology 86:902-910.

Guo, Q. F. 2003. Temporal species richness-biomass relationships along successional gradients. Journal of Vegetation Science 14:121-128.

Hector, A., and R. Bagchi. 2007. Biodiversity and ecosystem multifunctionality. Nature 448:188-190.

Hooper, D. U., et al. 2005. Effects of biodiversity on ecosystem functioning: A consensus of current knowledge. Ecological Monographs 75:3-35.

Hooper, D. U., and P. M. Vitousek. 1997. The effects of plant composition and diversity on ecosystem processes. Science 277:1302-1305.

Huston, M. A. 1997. Hidden treatments in ecological experiments: re-evaluating the ecosystem function of biodiversity. Oecologia 110:449-460.

Isbell, F. I., D. A. Losure, K. A. Yurkonis, and B. J. Wilsey. 2008. Diversity-productivity relationships in two ecologically realistic rarity-extinction scenarios. Oikos 117:996-1005.

Isbell, F. I., H. W. Polley, and B. J. Wilsey. 2009. Species interaction mechanisms maintain grassland plant species diversity. Ecology 90:1821-1830.

Jiang, L., S. Q. Wan, and L. H. Li. 2009. Species diversity and productivity: why do results of diversity-manipulation experiments differ from natural patterns? Journal of Ecology 97:603-608.

Keer, G. H., and J. B. Zedler. 2002. Salt marsh canopy architecture differs with the number and composition of species. Ecological Applications 12:456-473.

Larsen, T. H., N. M. Williams, and C. Kremen. 2005. Extinction order and altered community structure rapidly disrupt ecosystem functioning. Ecology Letters 8:538-547.

Lindig-Cisneros, R., and J. B. Zedler. 2002. Halophyte recruitment in a salt marsh restoration site. Estuaries $25: 1174-1183$.

Naeem, S. 2006. Biodiversity and ecosystem functioning in restored ecosystems: extracting principles for a synthetic perspective. Pages $210-237$ in D. Falk, M. A. Palmer, and J. B. Zedler, editors. Foundations of restoration ecology. Island Press, Washington, D.C., USA.

O'Brien, E. L., and J. B. Zedler. 2006. Accelerating the restoration of vegetation in a southern California salt marsh. Wetlands Ecology and Management 14:269-286.

Onuf, C. P., and M. L. Quammen. 1987. The biota: distribution and abundance. Pages 38-67 in C. P. Onuf, editor. The ecology of Mugu Lagoon, California: an estuarine profile. U.S. Fish and Wildlife Service Biological Report 85(7.15).

Palmer, M. A., and S. Filoso. 2009. Restoration of ecosystem services for environmental markets. Science 325:575-576.

Pennings, S. C., and R. M. Callaway. 1992. Salt-marsh plant zonation: the relative importance of competition and physical factors. Ecology 73:681-690.

Pfisterer, A. B., J. Joshi, B. Schmid, and M. Fischer. 2004. Rapid decay of diversity-productivity relationships after invasion of experimental plant communities. Basic and Applied Ecology 5:5-14.

Pywell, R. F., J. M. Bullock, D. B. Roy, L. I. Z. Warman, K. J. Walker, and P. Rothery. 2003. Plant traits as predictors of performance in ecological restoration. Journal of Applied Ecology 40:65-77.

R Development Core Team. 2008. R: A language and environment for statistical computing. R Foundation for Statistical Computing, Vienna, Austria. 〈http://www. R-project.org $\rangle$ 
Romanuk, T. N., R. J. Vogt, and J. Kolasa. 2009. Ecological realism and mechanisms by which diversity begets stability. Oikos 118:819-828.

Roscher, C., V. M. Temperton, N. Buchmann, and E. D. Schulze. 2009. Community assembly and biomass production in regularly and never weeded experimental grasslands. Acta Oecologia 35:206-217.

Schlapfer, F., A. B. Pfisterer, and B. Schmid. 2005. Nonrandom species extinction and plant production: implications for ecosystem functioning. Journal of Applied Ecology 42:13-24.

Schmid, B., et al. 2009. Consequences of species loss for ecosystem functioning: Meta-analyses of data from biodiversity experiments. Pages 14-29 in S. Naeem, D. Bunker, A. Hector, M. Loreau, and C. Perrings, editors. Biodiversity, ecosystem functioning, and human wellbeing: an ecological and economic perspective. Oxford University Press, Oxford, UK.

Sluis, W. J. 2002. Patterns of species richness and composition in re-created grassland. Restoration Ecology 10:677-684.

Smith, M. D., and A. K. Knapp. 2003. Dominant species maintain ecosystem function with non-random species loss. Ecology Letters 6:509-517.

Solan, M., B. J. Cardinale, A. L. Downing, K. A. M. Engelhardt, J. L. Ruesink, and D. S. Srivastava. 2004. Extinction and ecosystem function in the marine benthos. Science 306:1177-1180.

Srivastava, D. S., and M. Vellend. 2005. Biodiversity-ecosystem function research: Is it relevant to conservation? Annual Review of Ecology, Evolution, and Systematics 36:267-294.

Sullivan, G., J. C. Callaway, and J. B. Zedler. 2007. Plant assemblage composition explains and predicts how biodiversity affects salt marsh functioning. Ecological Monographs 77:569-590.

Sullivan, G., and J. B. Zedler. 1999. Functional redundancy among tidal marsh halophytes: a test. Oikos 84:246-260.

Thompson, K., A. P. Askew, J. P. Grime, N. P. Dunnett, and A. J. Willis. 2005. Biodiversity, ecosystem function and plant traits in mature and immature plant communities. Functional Ecology 19:355-358.

Thompson, R., and B. M. Starzomski. 2007. What does biodiversity actually do? A review for managers and policy makers. Biodiversity and Conservation 16:1359-1378.

Tilman, D. 1999. The ecological consequences of changes in biodiversity: a search for general principles. Ecology 80:1455-1474.

Tilman, D., J. Knops, D. Wedin, P. Reich, M. Ritchie, and E. Siemann. 1997. The influence of functional diversity and composition on ecosystem processes. Science 277:1300-1302.

Tilman, D., P. B. Reich, and J. M. H. Knops. 2006. Biodiversity and ecosystem stability in a decade-long grassland experiment. Nature 441:629-632.
Tylianakis, J. M., T. A. Rand, A. Kahmen, A. M. Klein, N. Buchmann, J. Perner, and T. Tscharntke. 2008. Resource heterogeneity moderates the biodiversity-function relationship in real world ecosystems. Plos Biology 6:947-956.

van Ruijven, J., and F. Berendse. 2009. Long-term persistence of a positive plant diversity-productivity relationship in the absence of legumes. Oikos 118:101-106.

Varty, A. K., and J. B. Zedler. 2008. How waterlogged microsites help an annual plant persist among salt marsh perennials. Estuaries and Coasts 31:300-312.

Wagner, K. I., S. K. Gallagher, M. Hayes, B. A. Lawrence, and J. B. Zedler. 2008. Wetland restoration in the new millennium: Do research efforts match opportunities? Restoration Ecology 16:367-372.

Wardle, D. A. 1999. Is "sampling effect" a problem for experiments investigating biodiversity-ecosystem function relationships? Oikos 87:403-407.

Wardle, D. A., and M. Jonsson. 2010. Biodiversity effects in real ecosystems - a response to Duffy. Frontiers in Ecology and the Environment 8:10-11.

Weis, J. J., B. J. Cardinale, K. J. Forshay, and A. R. Ives. 2007. Effects of species diversity on community biomass production change over the course of succession. Ecology 88:929939.

Wilsey, B. J., and H. W. Polley. 2004. Realistically low species evenness does not alter grassland species-richness-productivity relationships. Ecology 85:2693-2700.

Wright, J., A. Symstad, J. M. Bullock, K. Engelhardt, L. Jackson, and E. Bernhardt. 2009. Restoring biodiversity and ecosystem function: Will an integrated approach improve results. Pages 167-177 in S. Naeem, D. Bunker, A. Hector, M. Loreau, and C. Perrings, editors. Biodiversity, ecosystem functioning, and human wellbeing: an ecological and economic perspective. Oxford University Press, Oxford, UK.

Zavaleta, E. S., and K. B. Hulvey. 2004. Realistic species losses disproportionately reduce grassland resistance to biological invaders. Science 306:1175-1177.

Zavaleta, E. S., and K. B. Hulvey. 2007. Realistic variation in species composition affects grassland production, resource use and invasion resistance. Plant Ecology 188:39-51.

Zavaleta, E. S., J. R. Pasari, K. B. Hulvey, and G. D. Tilman. 2010. Sustaining multiple ecosystem functions in grassland communities requires higher biodiversity. Proceedings of the National Academy of Sciences USA 107:1443-1446.

Zedler, J. B. 2010. How frequent storms affect wetland vegetation: a preview of climate change impacts. Frontiers in Ecology and the Environment [doi:10.1890/090109].

Zedler, J. B., H. Morzaria-Luna, and K. Ward. 2003. The challenge of restoring vegetation on tidal, hypersaline substrates. Plant and Soil 253:259-273.

Zedler, J. B., and J. M. West. 2008. Declining diversity in natural and restored salt marshes: a 30-year study of Tijuana Estuary. Restoration Ecology 16:249-262. 